\title{
What Makes Vietnamese (Not) Attend Periodic General Health Examinations? A 2016 Cross-sectional Study
}

\author{
Quan-Hoang Vuong ${ }^{\mathrm{a}}$, Quang-Hoi Vu ${ }^{\mathrm{b}}$, Thu-Trang Vuong ${ }^{\mathrm{c}}$
}

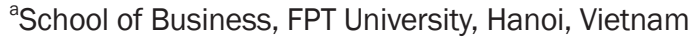

${ }^{b}$ FPT School of Business Bitexco Group, Hanoi, Vietnam

${ }^{\mathrm{c}}$ Sciences Po Paris, Campus Européen de Dijon, Dijon, France

Objectives: General health examinations (GHE) have become an increasingly common measure for preventive medicine in Vietnam. However, little is known about the factors among Vietnamese people who attend or miss GHE. Budget or time constraints remain to be evaluated for better-informed policy making. This study investigates factors affecting behaviors in attending periodic GHE. The main objectives are as follows: (1) to explore empirical relationships between influencing factors and periodic GHE frequencies, and (2) to predict the probabilities of attending GHE under associated conditions.

Methods: The study used a 2,068-observational dataset, obtained from a Vietnamese survey in 2016. The analysis was then performed using the methods of baseline-category logits for establishing relationships between predictor and response variables.

Results: Significant relationships were found among the expenditure and time consumption, health priority and sensitivity to health data, insurance status, and frequency of GHE, with most $p$-values $=0.01$.

Conclusion: Generally, people attended the GHE when they had the resources and health priorities (72.7\% probability). Expenditure and time remain key obstacles to the periodic GHE. Health priority and health data are important in improving rates for GHEs. Health insurance should play a positive role in promoting the GHE.

Key Words: general health examination, health insurance, medical costs, health service consumers, Vietnam

\section{INTRODUCTION}

Along with the rise in income and life standards, periodic health examinations and health care become more and more crucial. In the United States, the first periodic general health examination (GHE) programs have been launched since the early 20th century, but it took some time before they gained proper attention among the population. Periodic GHEs are considered a positive solution to lower mortality rates [1] and provide people with a chance to access health care resources [2], especially for children and elderly [3-5], by closely following their health status and, in case of illness, detecting possible symptoms early on [6-8], making it possible to receive timely, appropriate treatment [4]. In this manner, one could see periodic GHEs as a necessity [7].
Corresponding author:

Quan-Hoang Vuong

E-mail: hoangvq@fsb.edu.vn

Received October 25, 2016.

Revised March 21, 2017.

Accepted April 4, 2017.

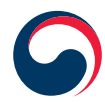

Centers for Disease Control \& Prevention

Copyright $\odot 2017$ Korea Centers for Disease Control and Prevention.

This is an open access article under the CC BYNC-ND license (http://creativecommons.org/ licenses/by-nc-nd/4.0/). 
However, does the periodic GHE truly work for everyone? In reality, there are instances in which a periodic GHE wastes not only medical resources and personnel for medical service providers but also time, energy, and money for the people who undergo these examinations [9]. Moreover, there is not enough evidence to conclude that people who have frequent GHEs would lead a longer, healthier life than those who do not have GHEs [3,9]; nor is there solid proof on the concrete benefits of GHE [10-18]. This uncertainty affects the mentality of both medical personnel and health service consumers.

At the same time, other elements tied to the undertaking of periodic GHE also greatly affect people's readiness to have frequent health checks. For example, the cost of medical examinations can greatly diminish participation in periodic GHE [7]. Another factor that drives people away from GHE is unnecessary examinations that may take up a large part of each medical check while causing extra costs [19-21]. Apart from the above, there are still people who do not have access to qualified medical services [22,23].

Faced with these shortcomings, health insurance is often used as solution to raise the frequency of GHEs among the population $[24,25]$. It has been well documented in the literature that insured people tend to have periodic GHEs more often [26-31] while most of those without health insurance only become hospitalized during an emergency, which usually leads to belated treatment and higher fatality rates $[32,33]$. On the other hand, opposed opinions have pointed out that health insurance merely incites people to use healthcare services more often rather than improving general health. In extreme cases, it might even aggravate a patient's condition as the medicines provided within the scope of insurance are not adequate to treat the illness $[27,30]$. Therefore, according to a survey conducted to find out the tendencies of studies, 51 of 54 studies on health insurance conclude in favor of, or partly in favor of, the positive correlation between having health insurance and health improvement [34].

Other than having health insurance, the habit of following up on one's own health is also a proponent to having more frequent GHEs. Most of these people visit clinics or hospitals for health checks [35-37]. A study focused on elderly people in China shows that, among those who come for a periodic GHE, the most frequent patients are either retired civil servants, with certain knowledge about health, or people with friends/relatives working in the medical sector [38]. This indicates that people with a certain knowledge or a reliable source of knowledge on healthcare are more inclined to hold health among their priorities.

Given the importance of healthcare in general and periodic GHE in particular, as well as the limits and contradictions present in the extant literature on GHE, it is necessary for new studies to further confirm and complement previously reported results.

This study aims to investigate psychological and sociodemographic factors that may possibly affect Vietnamese health consumers' behaviors with respect to periodic GHE. The major objectives are to: i) explore empirical relationships between factors in considerations and periodic GHE frequencies; and ii) predict the probabilities of attending GHE conditional upon factors whose influences are established by the empirical data. Thus, the subsequent analysis is performed with the purpose of answering these important questions: What makes people attend periodic GHEs, and what conditions will make sure the practice becomes possible for society?

The identification and confirmation of the significance of discernible factors through empirical evidence will later help suggest improvements for public health policy [39].

\section{MATERIALS AND METHODS}

The data, consisting of 2,068 observations, have been collected from surveys at clinics, schools, companies, and households in Hanoi and nearby provinces, which were conducted during September to October 2016.

The investigation was a random selection of individuals (i.e., not chosen based on any criteria). Vuong \& Associates (V\&A) is the main responsible of data collecting, with ethical standards stated in the surveying institution's Decision V\&A/07/2016 dated September 15,2016 . The data team directly gathers signed questionnaires with consent and cooperation from participants. The questionnaires were then checked and signed off by a team member, supervising person, head of V\&A and principal researcher.

\section{Statistical analysis}

Raw data were entered in Microsoft Excel before being converted into comma-separated values (CSV) format. Data treatment and categorical structuring for multi-way contingency data tables were executed in R 3.3.1. Estimates were analyzed using baseline-category logits model (BCL) model as specified in [38], enabling the detecting of empirical relations between nominal variables. Both response and predictor variables in this study were categorical variables. The multinomial logistic regression model was used to predict the likelihood of a category of the dependent variable $\mathrm{Y}$ in various conditions of the independent variable $\mathbf{x}$ and to evaluate the impact of dependent variables, as well as their tendencies to change when the independent variable changes.

Despite a log-linear specification being a possible choice, the application of logistic regression proves to be more efficient be- 
cause: (a) the model is comprised of predetermined number of variables, thus showing each variable's significance more clearly; and (b) explanations for estimated coefficients in empirical calculations can be acquired directly. It is also noteworthy that the BCL model can provide the odds ratio between a baseline category and any category within one variable.

The general equation of the baseline-categorical logit model is:

$$
\ln \frac{\pi_{j}(\mathrm{x})}{\pi_{J}(\mathrm{x})}=\alpha_{\mathrm{j}}+\beta_{\mathrm{j}}^{\prime} \mathrm{x}, j=1, \ldots, J-1 .
$$

in which $\mathbf{x}$ is the independent variable; and $\pi_{\mathrm{j}}(\mathrm{x})=\mathrm{P}(\mathrm{Y}=\mathrm{j} \mid \mathrm{x})$ its probability. Thus $\pi_{\mathrm{j}}=P\left(Y_{i j}=1\right)$ with $Y$ being the dependent variable.

In the logit model in consideration, the probability of an event is calculated as:

$$
\pi_{j}(\mathrm{x})=\frac{\exp \left(\alpha_{j}+\beta_{j}^{\prime} \mathrm{x}\right)}{1+\sum_{h=1}^{J-1} \exp \left(\alpha_{h}+\beta_{h}^{\prime} \mathrm{x}\right)}
$$

with $\Sigma_{j} \pi_{j}(\mathrm{x})=1 ; \alpha_{J}=0$ and $\beta_{J}=0$; in which $n$ is the number of observations in the sample, $j$ the categorical values of an observation $i$, and $h$ a row in basic matrix $\mathrm{X}_{i}$. Estimated probabilities can be used to predict the possibility of the person's last GHE (less than a year, more than a year, or not recalled) under certain conditions of hesitation due to cost and time consumption or readiness because health is a priority or because attending health checks is part of the habit and in relation to the respondent's health insurance status [39-41].

Estimated coefficients are computed through multivariable logistic regression and are used to calculate empirical probabilities. The statistical significance of predictor variables in the model are determined based on $z$-value and $p$-value; with $p<0.05$ being the conventional level of statistical significance required for a positive result [42].

\section{Data set}

The collected data reflect the respondent's answer on the reasons to their hesitation/readiness to attend GHE. At the same time, the study also evaluates the influence of health insurance (or lack thereof) and the reasons of hesitation/readiness on the length of time since the respondent's last heath check.

When considering their hesitation towards GHE, reasons include their view of GHE as incurring much consumption of time (Wsttime) or causing a concern about related expenditures (Wstmon). As for those who attend their GHEs, the two reasons mentioned are the fact that health is their top priority in life (HthyPriority) and that they frequently follow updates on their health status, as well as information regarding society's general health matters (FlwHealth). These variables are dichotomous, consisting of "Yes" and "No" categories.

In the same manner, the variable representing the presence of health insurance (HealthIns) also has the value of Yes (insured) or No (uninsured).

The response variable is the time since the person's last GHE (RecPerExam), with three categories: (1) less12: last GHE in less than 12 months; (2) g12: Last GHE in 12 months or more; and

\begin{tabular}{|c|c|}
\hline Characteristic & Data, n (\%) \\
\hline \multicolumn{2}{|l|}{ Age $(y)$} \\
\hline$<30$ & $1,306(63.15)$ \\
\hline $30-49$ & $643(31.09)$ \\
\hline$\geq 50$ & $119(5.75)$ \\
\hline \multicolumn{2}{|l|}{ Sex } \\
\hline Male & $728(35.20)$ \\
\hline Female & $1,340(64.80)$ \\
\hline \multicolumn{2}{|l|}{ Education } \\
\hline Junior high school & $142(6.87)$ \\
\hline High school & $416(20.12)$ \\
\hline University/College & $1,383(66.88)$ \\
\hline Post-graduate & $127(6.14)$ \\
\hline \multicolumn{2}{|l|}{ Health insurance } \\
\hline Yes & $1,700(82.21)$ \\
\hline No & $368(17.79)$ \\
\hline \multicolumn{2}{|c|}{ Hesitation due to consumption of time } \\
\hline Yes & $1,069(51.69)$ \\
\hline No & $999(48.31)$ \\
\hline \multicolumn{2}{|c|}{ Hesitation due to related expenditures } \\
\hline Yes & $770(37.23)$ \\
\hline No & $1,298(62.77)$ \\
\hline \multicolumn{2}{|c|}{ Readiness due to health as a top priority } \\
\hline Yes & $1,675(81.00)$ \\
\hline No & $393(19.00)$ \\
\hline \multicolumn{2}{|c|}{ Readiness due to sensitivity to health matters } \\
\hline Yes & $977(47.24)$ \\
\hline No & $1,091(52.76)$ \\
\hline \multicolumn{2}{|c|}{ Time since last general health examination } \\
\hline Less than 12 months & $1,059(51.21)$ \\
\hline 12 months or more & $493(23.84)$ \\
\hline Unknown (not recalled) & $516(24.95)$ \\
\hline
\end{tabular}

Table 1. Basic survey statistics 
(3) unknown: the respondent does not remember or has not attended GHE ever.

Most participants were in their twenties, with the sample's average age at approximately 29 years old $(63.15 \%<30$ years $)$. Females were more willing to answer questionnaires than males (64.80\% were female); university graduates made up the largest portion of the sample (66.88\%). As health insurance has become obligatory, $82.21 \%$ participants were insured. The average time for fully answering one questionnaire was between 7 to 15 minutes.

Table 1 shows that, among 2,068 participants, concerns that GHE might be a waste of time was the main cause for their hesitation (nearly $52 \%$ participants chose this as a reason). In addition, > 37\% stated GHE expenditures as a concern. As for the reasons for readiness to have medical checks, health being a top priority turned out to be the most favored answer (81\%), followed by respondents' receptiveness and sensitivity to updates on general health matters and society's concerns (> 47\%). The GHE appeared to be gaining attention, with 1,059 people $(51.21 \%)$ attending a GHE within 12 months.

\section{RESULTS}

Employing logistic regression estimations with dependent variable RecPerExam against five independent variables, Wsttime, Wstmon, HthyPriority, FlwHealth, and HealthIns, (from the multi-way contingency table provided in Supplementary Table S1) yielded the results reported in Table 2.

Estimated coefficients and reported test statistics (Table 2) suggested that there existed relationships between the resource factors (money, time), psychological factors (health priority, information update), macro policy factor (health insurance), and practice of attending a periodic GHE. These relationships are presented in functional forms of Equations 1 and 2, as follows.

$$
\begin{aligned}
\ln \left(\frac{\pi_{\text {unknown }}}{\pi_{\text {less12 }}}\right)= & -0.053+0.289 \times \text { Yes. Wsttime }+ \\
& 0.581 \times \text { Yes.Wstmon }-0.107 \times \\
& \text { Yes.HthyPriority }-0.732 \times \\
& \text { Yes.FlwHealth }-0.740 \times \text { Yes.HealthIns }
\end{aligned}
$$

$$
\begin{aligned}
\ln \left(\frac{\pi_{\mathrm{g} 12}}{\pi_{\text {less12 }}}\right)= & -0.098+0.662 \times \text { Yes.Wsttime }+ \\
& 0.474 \times \text { Yes.Wstmon }-0.578 \times \quad \text { (Equation 2) } \\
& \text { Yes.HthyPriority }-0.354 \times \quad \\
& \text { Yes.FlwHealth }-0.686 \times \text { Yes.HealthIns }
\end{aligned}
$$

Table 3 presents the distributions of the probability of time gaps for the respondents' most recent GHE participations, conditional upon reasons for hesitation (resource constraints such as money and time), readiness (psychological factors), and health insurance status (macro policy influence).

From the regression equations (Equations 1 and 2), it can be remarked that variables Wsttime, Wstmon receive positive coefficients $(+)$ while coefficients for variables HthyPriority, FlwHealth are negative (-). This observation shows influences in opposite directions between reasons of hesitation and reasons of readiness towards GHE. In addition, the magnitude of Wsttime is larger than that of Wstmon in Equation 1, suggesting that for those with stronger propensity to attend a periodic GHE ( $<12$-month time gap), the consumption of time is of greater concern than the medical expenditure.

It is also noteworthy that HealthIns has the highest absolute values for estimated coefficients, $\left|\beta_{5}\right|$, being 0.740 and $0.686(p<$ $0.001)$, respectively. These values suggest that health insurance has the most influence on the time gap since respondents' last GHE.

The largest number in Table 3 shows that insured persons who do not hesitate to attend GHE for time or money reasons, and who have set a higher priority for health matters and had sensitivity to health status/updates, are the most likely (72.7\%) to attend periodic GHE.

\begin{tabular}{|c|c|c|c|c|c|c|}
\hline & $\begin{array}{l}\text { Intercept } \\
\left(\beta_{0}\right)\end{array}$ & $\begin{array}{c}\text { Wsttime }=\text { yes } \\
\left(\beta_{1}\right)\end{array}$ & $\begin{array}{c}\text { Wstmon }=\text { yes } \\
\left(\beta_{2}\right)\end{array}$ & $\begin{array}{l}\text { HthyPriority = yes } \\
\qquad\left(\beta_{3}\right)\end{array}$ & $\begin{array}{c}\text { FlwHealth }=\text { yes } \\
\left(\beta_{4}\right)\end{array}$ & $\begin{array}{c}\text { FlwHealth }=\text { yes } \\
\left(\beta_{5}\right)\end{array}$ \\
\hline Logit (unknown|less12) & $\begin{array}{c}-0.053 \\
{[-0.306]}\end{array}$ & $\begin{array}{r}0.289^{*} \\
{[2.343]}\end{array}$ & $\begin{array}{l}0.581^{* * *} \\
{[4.599]}\end{array}$ & $\begin{array}{c}-0.107 \\
{[-0.711]}\end{array}$ & $\begin{array}{l}-0.732^{\star * \star} \\
{[-6.242]}\end{array}$ & $\begin{array}{l}-0.740^{\star * *} \\
{[-5.174]}\end{array}$ \\
\hline Logit (g12|less12) & $\begin{array}{c}-0.098 \\
{[-0.562]}\end{array}$ & $\begin{array}{l}0.662^{* * *} \\
{[5.243]}\end{array}$ & $\begin{array}{l}0.474^{* * *} \\
{[3.713]}\end{array}$ & $\begin{array}{l}-0.578^{* * *} \\
{[-3.990]}\end{array}$ & $\begin{array}{l}-0.354^{* *} \\
{[-2.983]}\end{array}$ & $\begin{array}{l}-0.686^{* * *} \\
{[-4.676]}\end{array}$ \\
\hline
\end{tabular}

Table 3 also reports empirical probabilities of the time gap since the person's most recent GHE, hesitant and ready to have health checks due to health being their first priority. The propensity to attend periodic GHE (less12) and propensity to avoid GHE (g12/unknown) move in opposite directions from no.flw to yes.flw. This tendency shows that being diligent on following their own health status raises the likelihood of having recently

Table 2. Estimation results for the main analysis

Significance codes: $0,{ }^{* *} 0.001,{ }^{*} 0.01,{ }^{*} 0.05$; z-value in [square brackets]; baseline category for: Wsttime $=$ no; Wstmon $=$ no; HthyPriority $=$ no; FlwHealth $=$ no; and HealthIns $=$ no. Log-likelihood: -151.22 on 52 degrees of freedom (df). Residual deviance: 91.22 on $52 \mathrm{df}$. 


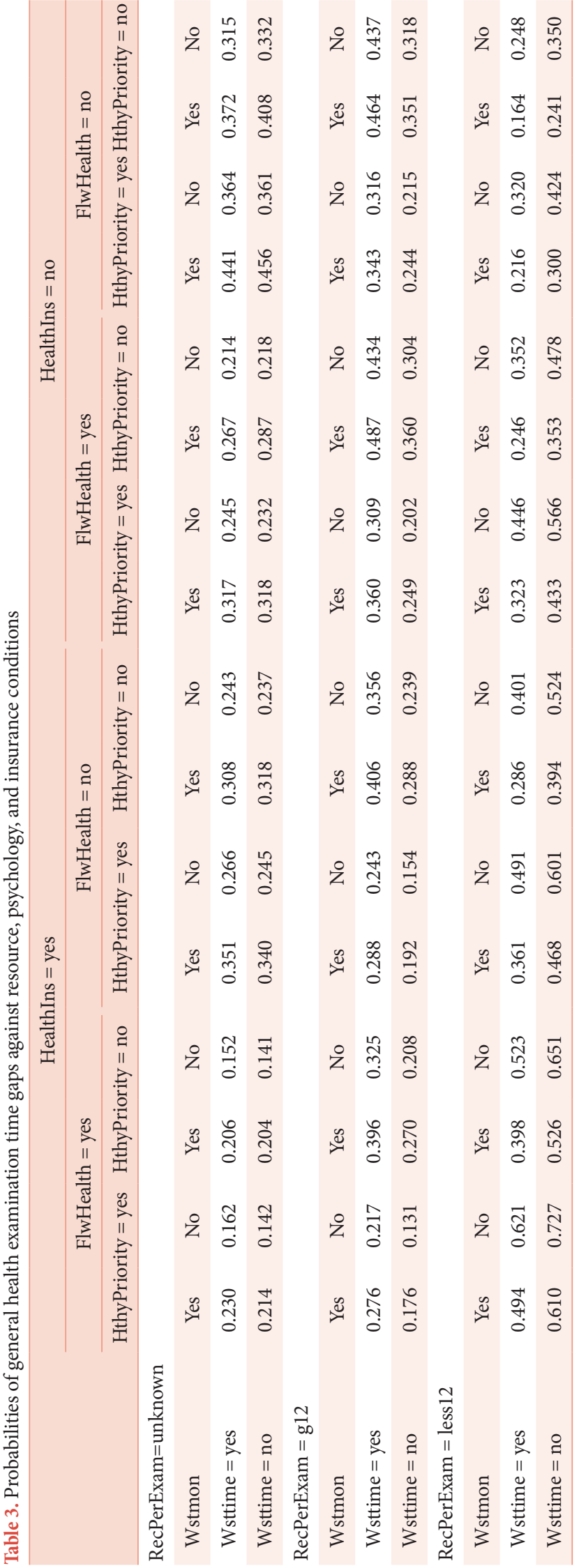

had a GHE among surveyed people. The same conclusion can be reached for those who give a high priority to their health status.

As for people who are ready to have GHE due to health being their first priority and sensitivity to health status/updates, as well as being not at all reluctant to check their health for reasons of time, the probabilities of them having recently had a GHE unveiled a rather expected prediction that when being free from financial concerns, people would likely show a strong propensity to attend periodic GHEs. The same effect is observed with those who see consumption of time for a GHE as costly.

In addition, the above results suggest that insured people, with or without financial concerns, are always more likely to attend periodic GHE. Meanwhile, for those who have no health insurance, the probability of attending GHE rises only when they are not worried about financial issues.

\section{DISCUSSION}

When worries about financial or time obstacles diminish, people tend to be more regularly attend GHE, as they do have the need and the means to examine their general health, even when no apparent symptoms prompt them to, in order to detect risks of illnesses early on and undergo appropriate treatment if required. On the other hand, when financial difficulties or dissatisfaction due to prolonged waiting time during GHE sessions come into play, people are much less willing to have periodic GHE. This avoidance does happen at their own peril.

This conclusion is intuitive, because a periodic GHE is expected to be a regular activity that costs add up to that of general healthcare costs. However, GHE are not a necessity, in the sense that it would be downsized from consumption when the household/individual budget becomes tight. Therefore, people with a lower income tend to only make medical appointments in case of apparent symptoms or even with an emergency. For these people, public hospitals are also a favored choice due to their lower costs. This often leads to public hospitals being overloaded with patients, thus prolonging waiting time for each patient, giving them a bad impression of health checks. Another consequence of hospitals being overloaded is the reduction in medical service quality. This reduced quality would in turn affect participants' mentality, making them reluctant to take the next appointment because the GHE did not give them adequate results while consuming a lot of their time.

Faced with these challenges, the priority and regularity in caring for one's health could in part lessen hesitation towards periodic GHEs. In fact, people with a true care for their health are often willing to spend time and money to obtain updates on their 
general health status. This, to them, is to minimize the risk of discovering illnesses only at critical necessity stages, thus avoiding much greater uncertainties and expensive treatments later.

Health insurance clearly has positive impacts on promoting the good practice of attending periodic GHE. Even when financial concerns exist, the insured are still more likely to have regular GHE. The reason is that costs are the most important factor hindering people from having GHE periodically $[7,19]$. In Vietnam, health insurance can reimburse up to $80 \%$ of all medical costs to patients, which is apparently an attractive benefit, especially to those with lower income. Moreover, with health insurance, people may opt for private clinics/hospitals, where services are more friendly and infrastructure no less adequate than public hospitals.

Based on results from the research, some solutions to promote periodic GHEs are recommended for the sake of better health [37]. Employers and social programs should allocate a reasonable budget to support employees/recipients in attending periodic GHE. In addition, health insurance benefits should adequately cover periodic GHE, in combination with lower expenditures as the health insurance agency has the power of negotiating with health services providers. There can also be a better flexibility for offers of GHEs, so that participants can choose relevant choices of medical tests/checks, making consumption of time less an obstacle. The public health authority may also need to do more with respect to educating the public about the value of GHE and providing them with updates and options, which helps the public make better-informed decisions about attending periodic GHEs, further validating early insights from [43].

A major limitation of this study is due to its geographical concentration on Hanoi and its vicinity. A nationwide survey may exhibit regional differences and behavior shifts, especially if control variates enter the analytical models. For the time being, this type of data set is beyond our capacity and will certainly require a much stronger research effort in the future.

\section{CONFLICTS OF INTEREST}

No potential conflict of interest relevant to this article was reported.

\section{ACKNOWLEDGMENTS}

The authors would like to thank several people at Vuong \& Associates and Quang-Vu-Hung Hoi (Foundation) for assistance in collecting and preparing the dataset for this research, particularly Dam Thu Ha, Do Thu Hang, Nguyen Thi Phuong, Nghiem Phu Kien Cuong, and Tran Thanh Tung. Special thanks are extended to the thousands of respondents participating in this survey, and especially Dang Tran Dung, CEO of Hospital 125 Thai Thinh (Hanoi), for his heartfelt support during the research process.

\section{REFERENCES}

1. Holland W. Periodic health examination: a brief history and critical assessment. Eurohealth 2010;15:16-20.

2. Ren A, Okubo T, Takahashi K. Comprehensive periodic health examination: impact on health care utilisation and costs in a working population in Japan. J Epidemiol Community Health 1994;48:47681. https://doi.org/10.1136/jech.48.5.476

3. Zielhuis GA. Are periodic school health examinations worthwhile? Health Policy 1985;5:241-53. https://doi.org/10.1016/0168 8510(85)90089-2

4. Wu HY, Yang LL, Zhou S. Impact of periodic health examination on surgical treatment for uterine fibroids in Beijing: a casecontrol study. BMC Health Serv Res 2010;10:329. https://doi. org/10.1186/1472-6963-10-329

5. Burton LC, Steinwachs DM, German PS, et al. Preventive services for the elderly: would coverage affect utilization and costs under Medicare? Am J Public Health 1995;85:387-91.

6. Nupponen R. Client views on periodic health examinations: opinions and personal experience. J Adv Nurs 1996;23:521-7. https://doi. org/10.1111/j.1365-2648.1996.tb00014.x

7. Oboler SK, Prochazka AV, Gonzales R, Xu S, Anderson RJ. Public expectations and attitudes for annual physical examinations and testing. Ann Intern Med 2002;136:652-9. https://doi.org/10.7326/00034819-136-9-200205070-00007

8. Roberts NJ. The values of limitations of periodic health examinations. J Chronic Dis 1959;9:95-116. https://doi.org/10.1016/0021 9681(59)90150-X

9. Howard-Tripp M. Should we abandon the periodic health examination?: YES. Can Fam Physician 2011;57:158-60.

10. Cutler JL, Ramcharan S, Feldman R, et al. Multiphasic checkup evaluation study. 1. Methods and population. Prev Med 1973;2:197206.

11. Dales LG, Friedman GD, Ramcharan S, et al. Multiphasic checkup evaluation study. 3. Outpatient clinic utilization, hospitalization, and mortality experience after seven years. Prev Med 1973;2:221-35.

12. Knox EG. Multiphasic screening. Lancet 1974;2:1434-6. https://doi. org/10.1016/S0140-6736(74)90086-5 
13. Friedman GD, Collen MF, Fireman BH. Multiphasic Health Checkup Evaluation: a 16-year follow-up. J Chronic Dis 1986;39:453-63.

14. Holland WW, Creese AL, D'Souza MF, et al; The South-East London Screening Study Group. A controlled trial of multiphasic screening in middle-age: results of the South-East London Screening Study. The South-East London Screening Study Group. Int J Epidemiol 1977;6:357-63. https://doi.org/10.1093/ije/6.4.357

15. Olsen DM, Kane RL, Proctor PH. A controlled trial of multiphasic screening. N Engl J Med 1976;294:925-30. https://doi. org/10.1001/10.1056/NEJM197604222941705

16. Elsom KA, Schor S, Clark TW, Elsom KO, Hubbard JP. Periodic health examination. Nature and distribution of newly discovered disease in executives. J Am Med Assoc 1960;172:5-10. https://doi. org/10.1001/jama.1960.03020010062003

17. Clark TW, Schor SS, Elsom KO, Hubbard JP, Elsom KA. The periodic health examination: evaluation of routine tests and procedures. Ann Intern Med 1961;54:1209-22. https://doi.org/10.7326/00034819-54-6-1209

18. Schor SS, Clark TW, Parkhurst LW, Baker JP, Elsom KA. An evaluation of the periodic health examination. The findings in $350 \mathrm{ex}-$ aminees who died. Ann Intern Med 1964;61:999-1005. https://doi. org/10.7326/0003-4819-61-6-999

19. Merenstein D, Daumit GL, Powe NR. Use and costs of nonrecommended tests during routine preventive health exams. Am J Prev Med 2006;30:521-7. https://doi.org/10.1016/j.amepre.2006.02.003

20. Cherrington A, Corbie-Smith G, Pathman DE. Do adults who believe in periodic health examinations receive more clinical preventive services? Prev Med 2007;45:282-9. https://doi.org/10.1016/ j.ypmed.2007.05.016

21. Boulware LE, Marinopoulos S, Phillips KA, et al. Systematic review: the value of the periodic health evaluation. Ann Intern Med 2007;146:289-300. https://doi.org/10.7326/0003-4819-146-4200702200-00008

22. Hutchison B, Woodward CA, Norman GR, Abelson J, Brown JA. Provision of preventive care to unannounced standardized patients. CMAJ 1998;158:185-93.

23. McGlynn EA, Asch SM, Adams J, et al. The quality of health care delivered to adults in the United States. N Engl J Med 2003;348:263545. https://doi.org/10.1056/NEJMsa022615

24. Manning WG, Newhouse JP, Duan N, Keeler EB, Leibowitz A, Marquis MS. Health insurance and the demand for medical care: evidence from a randomized experiment. Am Econ Rev 1987;77:25177.

25. Ross CE, Mirowsky J. Does medical insurance contribute to socioeconomic differentials in health? Milbank Q 2000;78:291-321, 1512. https://doi.org/10.1111/1468-0009.00171

26. Lurie N, Ward NB, Shapiro MF, Brook RH. Termination from MediCal--does it affect health? N Engl J Med 1984;311:480-4. https://doi. org/10.1056/NEJM198408163110734

27. Lurie N, Ward NB, Shapiro MF, Gallego C, Vaghaiwalla R, Brook RH. Termination of Medi-Cal benefits. A follow-up study one year later. N Engl J Med 1986;314:1266-8. https://doi.org/10.1056/ NEJM198605083141934

28. Meer J, Rosen HS. Insurance and the utilization of medical ser- vices. Soc Sci Med 2004;58:1623-32. https://doi.org/10.1056/ NEJM198605083141934

29. Lu JF, Hsiao WC. Does universal health insurance make health care unaffordable? Lessons from Taiwan. Health Aff (Millwood) 2003;22:77-88. https://doi.org/10.1377/hlthaff.22.3.77

30. Wilper AP, Woolhandler S, Lasser KE, McCormick D, Bor DH, Himmelstein DU. Health insurance and mortality in US adults. Am J Public Health 2009;99:2289-95. https://doi.org/10.2105/ AJPH.2008.157685

31. Oster A, Bindman AB. Emergency department visits for ambulatory care sensitive conditions: insights into preventable hospitalizations. Med Care 2003;41:198-207.

32. Hadley J. Sicker and poorer--the consequences of being uninsured: a review of the research on the relationship between health insurance, medical care use, health, work, and income. Med Care Res Rev 2003;60(2 Suppl):3S-75S; discussion 76S-112S.

33. Boland BJ, Scheitel SM, Wollan PC, Silverstein MD. Patient-physician agreement on reasons for ambulatory general medical examinations. Mayo Clin Proc 1998;73:109-17. https://doi.org/10.1016/ S0025-6196(11)63641-0

34. DeFriese GH, Hetherington JS. The "periodic physical examination" as a strategy for prevention in clinical practice. Mobius 1981;1:59-65. https://doi.org/10.1002/chp.4760010309

35. Boland BJ, Wollan PC, Silverstein MD. Yield of laboratory tests for case-finding in the ambulatory general medical examination. Am J Med 1996;101:142-52. https://doi.org/10.1016/S00029343(96)80068-4

36. Sun X, Chen Y, Tong X, et al. The use of annual physical examinations among the elderly in rural China: a cross-sectional study. BMC Health Serv Res 2014;14:16. https://doi.org/10.1186/1472-6963-1416

37. Quan-Hoang V. Information expensiveness perceived by Vietnamese patients with respect to healthcare provider's choice. Acta Inform Med 2016;24:360-3. https://doi.org/10.5455/aim.2016.24.360-363

38. Agresti A. Categorical data analysis. 3rd ed. Hoboken, NJ: Wiley; 2013.

39. Vuong QH. Be rich or don't be sick: estimating Vietnamese patients' risk of falling into destitution. Springerplus 2015;4:529. https://doi. org/10.1186/s40064-015-1279-x

40. Vuong QH, Nguyen H, Vuong TT. Health insurance thresholds and policy implications: a Vietnamese medical survey in 2015. Biomed Res 2017;28:2432-8.

41. Vuong QH, Nguyen H. Patients' contributions as a quid pro quo for community supports? Evidence from Vietnamese co-location clusters. Int J Bus Soc 2017;18:189-210.

42. Agresti A. Modeling Ordinal Categorical Data, University of Florida [Internet]. Department of Statistics, University of Florida; 2013 [cited 2017 Jan 10]. Available from: http://www.stat.ufl.edu/ aa/ordinal/ agresti_ordinal_tutorial.pdf.

43. Vuong QH. Health communication, information technology and the public's attitude toward periodic general health examinations. F1000Res 2016;5:2935. https://doi.org/10.12688/f1000research.10508.1 